\title{
Paternidade Adolescente: Um Estudo sobre Autopercepçóes do Fenômeno
}

\author{
Teenage Fatherhood: A Study on Self-perceptions of the Phenomenon
}

\author{
Geanne Pereira Alves Paulino ${ }^{\mathrm{I}}$ \\ Naiana Dapieve Patias ${ }^{\mathrm{I}}$ \\ Ana Cristina Garcia Dias ${ }^{\mathrm{I}}$
}

\begin{abstract}
Resumo
Ser pai prematuramente, em alguns contextos, pode causar preocupação e resistência no meio social. Este trabalho teve como objetivo compreender alguns aspectos envolvidos no fenômeno da paternidade adolescente, como, por exemplo, as principais mudanças identificadas na vida de pais adolescentes e as concepçóes sobre paternidade dos mesmos. Utilizaram-se como instrumento de coleta de dados entrevistas semiestruturadas com três pais adolescentes de uma cidade do interior do Rio Grande do Sul. As entrevistas foram analisadas por meio da análise de conteúdo categorial temática. Apesar de a paternidade na adolescência ser um acontecimento náo esperado, os participantes perceberam ganhos com o advento da gravidez e, consequentemente, da paternidade. A responsabilidade foi apontada como um fator positivo em suas vidas, na medida em que os fez procurar outras formas de viver diante da situação.
\end{abstract}

Palavras-chave: Paternidade; adolescência; psicologia do adolescente.

\section{Abstract}

Being a father early, in some contexts, can cause worry and resistance in the social environment. This study aimed to understand some aspects involved in the phenomenon of adolescent fatherhood, for example, the major identified changes in the lives of teenage parents and their notions about parenthood. Semi-structured interviews were used as an instrument of data collection with three teenage fathers in a city of the state of Rio Grande do Sul. The interviews were analyzed through thematic category content analysis. Although paternity in adolescence is an unexpected event, the participants realized gains with the advent of pregnancy, and consequently, of fatherhood. The responsibility was identified as a positive factor in their lives, as it has made them look for other ways to live in this situation.

Keywords: Fatherhood; adolescence; adolescent psychology.

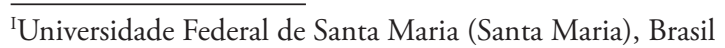

A gravidez na adolescência tem se tornado um assunto de interesse não só no meio acadêmico como também tem se revelado uma preocupaçáo no âmbito social, governamental e público. Alguns autores consideram a gravidez na adolescência um "problema social” e de Saúde Pública, que traz consequências negativas para as vidas dos jovens, uma vez que interfere nos projetos de escolarização e inserção no mundo do trabalho (Jorgensen,1993; Levandowski, 2001; Moreira, Viana, Queiroz \& Jorge, 2008; Trindade \& Menandro, 2002). A relevância na investigação desse tema tornou-se mais evidente quando realizamos a busca sobre o fenômeno em portais de periódicos. Por exemplo, em consulta realizada no ano de 2012 no portal SciELO (www.scielo.br), com os descritores "paternidade" e "maternidade" em separado, foram identificados 1.004 artigos sobre o tema da maternidade e apenas 132 sobre a paternidade. Quando os descritores foram acrescentados ao descritor "adolescência", foram encontrados 74 artigos com "maternidade" e apenas 24 relativos à "paternidade”. Então, percebemos que a grande maioria dos pesquisadores direciona o enfoque de suas pesquisas sobre gravidez $\mathrm{e}$ parentalidade na adultez e, principalmente, na adolescência, para a perspectiva feminina do fenômeno. De fato, Levandowski (2001) aponta que a incidência de estudos sobre a maternidade é aproximadamente três vezes maior quando comparada ao tema da paternidade, sendo o mesmo verdadeiro quando isso acontece durante a adolescência. Consideramos, então, importante desenvolver estudos que possibilitem aprofundar conhecimentos sobre o fenômeno da paternidade du- 
rante a adolescência, buscando identificar as mudanças ocorridas nas vidas desses pais adolescentes e suas concepçôes sobre paternidade.

Reis (1997) definiu a paternidade adolescente como aquela experiência na qual o indivíduo se torna pai antes de completar os 20 anos de idade. Contudo, esse mesmo autor reconhece que "esta definiçáo deixa de lado consideraçóes a respeito do relativismo social, cultural, étnico e psicológico da ideia geral de paternidade" (p. 70). Ser pai prematuramente, segundo algumas convençóes culturais, pode causar preocupação e resistência no meio social, pois a adolescência, de maneira geral, é concebida como um período no qual o indivíduo ainda se encontra em formação tanto biologicamente quanto psicologicamente. De fato, nesse período, os adolescentes passam por diferentes mudanças de ordem física, cognitiva e social; desta forma, não estariam preparados para assumir todas as responsabilidades inerentes à paternidade, que, por sua vez, se encontram diretamente associadas à inserçâo na vida adulta (Grossman, 2010; Levandowski, Koller \& Piccinini, 2002). A adolescência também é geralmente percebida como uma fase do desenvolvimento em que os jovens vivem contradiçóes, confusôes e ambivalências que afetam tanto o adolescente como o seu meio familiar e social. Assim, a experiência de parentalidade náo seria esperada no período, pois acarretaria maiores conflitos para o indivíduo e para seu ambiente familiar, em um período no qual alguns conflitos já estariam presentes em função de questôes de reestruturaçóes de identidade e papéis (Levandowski et al., 2002).

O presente trabalho teve como objetivo conhecer o que jovens pais têm a dizer sobre sua experiência de paternidade, podendo-se, assim, compreender alguns aspectos do fenômeno da paternidade durante a adolescência e identificar as mudanças ocorridas na vida desses pais adolescentes e suas concepçóes sobre paternidade. Esperamos que, por meio deste estudo, seja possível contribuir com conhecimentos que auxiliem na construção de projetos de políticas públicas voltados à situação da paternidade na adolescência e que promovam a qualidade de vida de jovens pais. Pretendemos, ainda, produzir conhecimentos e fornecer informaçóes aos profissionais de saúde envolvidos com esse público, para que os mesmos possam conhecer as realidades desses pais. Parte-se do pressuposto de que conhecer essa realidade pode auxiliar a construção de intervenções, que respeitarão as necessidades, diferenças etárias, geracionais, sociais e culturais dessa população. Nesse sentido, o profissional poderá atuar de forma mais adaptada e integrada ao público-alvo, sem impor a esses jovens suas concepçóes de crenças e valores, bem como aquelas referentes à vivência do adulto.

\section{Método}

Participaram deste estudo 3 adolescentes, todos com idade de 18 anos, que estavam passando pela situação de paternidade durante a adolescência. Todos os participantes foram recrutados, durante o período de coleta, em uma Unidade Básica de Saúde de uma cidade do interior do Rio Grande do Sul. Os participantes estão com nomes fictícios, a fim de preservar sua privacidade. Na Tabela 1, estão as informaçôes sociodemográficas dos pais entrevistados.

$\mathrm{O}$ número reduzido de pais voluntários para a pesquisa ocorreu devido às dificuldades de se estabelecer contato com os mesmos, uma vez que ou esses pais nem sempre acompanhavam as mães nas consultas de pré-natal por estarem trabalhando ou não terem contato com a mãe. Outro motivo que fez com que a amostra ficasse reduzida foi os pais adolescentes não concordarem em participar do estudo. Nesse sentido, questóes de gênero podem explicar

Tabela 1. Informaçóes sociodemográficas dos participantes

\begin{tabular}{lcclccc}
\hline Participantes & Idade & Escolaridade & Profissáo & $\begin{array}{c}\text { Situaçáo } \\
\text { conjugal }\end{array}$ & $\begin{array}{c}\text { Idade da } \\
\text { companheira }\end{array}$ & $\begin{array}{c}\text { Idade do } \\
\text { filho }\end{array}$ \\
\hline $\begin{array}{l}\text { Gerson } \\
\text { (gravidez náo planejada) }\end{array}$ & 18 anos & $\begin{array}{c}\text { Ensino médio } \\
\text { incompleto }\end{array}$ & Estudante & Solteiro & 16 anos & 11 meses \\
$\begin{array}{l}\text { Giovanni } \\
\text { (gravidez náo planejada) }\end{array}$ & 18 anos & $\begin{array}{c}\text { Ensino médio } \\
\text { completo }\end{array}$ & Pintor & $\begin{array}{l}\text { Mora junto à } \\
\text { companheira }\end{array}$ & 15 anos & 10 meses \\
$\begin{array}{l}\text { Gilson } \\
\text { (gravidez planejada) }\end{array}$ & 18 anos & $\begin{array}{c}\text { Ensino médio } \\
\text { completo }\end{array}$ & Motoboy & $\begin{array}{l}\text { Mora junto à } \\
\text { companheira }\end{array}$ & 21 anos & $3^{\circ}$ trimestre \\
gestacional
\end{tabular}


esse fenômeno, uma vez que falar das próprias experiências e sentimentos está mais vinculado ao papel feminino do que ao masculino. Desta forma, os homens podem não estar habituados a se expressar verbalmente.

O fato de um dos participantes da pesquisa ainda não ter o bebê nascido não foi foco de nosso estudo. $\mathrm{O}$ mesmo foi preservado na amostra, pois não foram identificadas maiores diferenças em seu relato no que tange aos objetivos do trabalho, quando realizamos as análises e comparamos seu depoimento ao dos demais participantes. Contudo, consideramos que maiores estudos são necessários para verificar possíveis diferenças entre as concepçóes e as transformaçóes na vida dos jovens pais antes e após o nascimento do filho.

Para a coleta dos dados, foi utilizada uma entrevista semiestruturada baseada em questóes construídas a partir da revisão de literatura. Essas questôes tinham o objetivo de investigar as experiências, sentimentos e expectativas desses pais em relação às suas vivências frente à própria paternidade, além de suas percepçôes e sentimentos sobre as mudanças ocorridas em sua vida e seus projetos de vida futuros, especialmente no que tange à escolarização e profissionalização.

No contato com os pais, foram explicados aos mesmos os objetivos do estudo, bem como procedimentos, além de outras informaçóes constantes no $\mathrm{ra}$ pport e no termo de consentimento livre e esclarecido, sendo os mesmos convidados a participar do estudo. Com os pais que concordaram em participar do estudo, foi marcado um encontro em local e horário da conveniência do participante, onde a entrevista se realizou. Este trabalho obteve aprovação do Comitê de Ética em Pesquisa da Universidade Federal de Santa Maria (UFSM).

As informaçôes obtidas nas entrevistas foram submetidas a uma análise de conteúdo categorial temática, conforme a proposta de Bardin (1977). A análise constituiu-se de três momentos cronológicos: a pré-análise, a exploração do material e o tratamento e interpretação dos resultados (Bardin, 1977). No primeiro momento, foi feita a organizaçáo do material, a transcrição das entrevistas e a leitura exaustiva das mesmas, possibilitando a formulação de questóes norteadoras e de indicadores que fundamentaram a interpretação final. Essa fase pôde ser decomposta em tarefas (Minayo, 1993). A primeira delas foi a leitura flutuante, que constitui em tomar contato exaustivo com o material. Foi por meio da leitura que surgiram as questôes norteadoras para o levantamento de todo o material suscetível de utilizaçáo. A segunda tarefa foi a constituição do corpus, ou seja, a organização do material. Esta visou cumprir as regras de: exaustividade (contemplar todo o corpus, sem nenhuma exclusão); representatividade (a amostra representou o universo pretendido); homogeneidade (os dados obedeceram às mesmas regras e referiram-se ao mesmo tema, utilizando-se as mesmas técnicas e o mesmo entrevistador); pertinência (os documentos adaptaram-se ao conteúdo e objetivo da pesquisa). A terceira tarefa foi a composição de ideias que mantinham relação e que poderiam ter explicação na literatura. Nessa fase de pré-análise, as palavras-chave ou frases (unidade de registro), a delimitação do contexto de compreensão, os recortes, a categorização e o aporte teórico foram determinados para posterior análise.

\section{Resultados e Discussão}

\section{Mudanças Pessoais}

Nesta categoria, são expostos e discutidos os resultados referentes às expectativas e sentimentos dos pais quanto às mudanças pessoais decorrentes do nascimento do filho, além de seus sentimentos diante da notícia da paternidade. Foram identificados, nas subcategorias, os temas: Reaçóes à notícia da gravidez e Maior responsabilidade e redução da liberdade.

\section{Reações à Notícia da Gravidez}

Dois participantes não planejaram a gravidez. Eles relataram que a notícia foi recebida como algo inesperado e se preocuparam em como informar sua própria família e a da menina. Já para o participante que teve a gravidez planejada, a notícia veio com alegria. De fato, autores como Meincke e Carraro (2009) destacam que, por se tratar de um acontecimento geralmente inesperado, a gravidez na adolescência pode causar uma reação de "choque", tanto para os pais adolescentes como para seus familiares. Nogueira, Martins, Schall e Modena (2011, p. 32) justificam que o medo da reação dos pais parece estar relacionado com a associação da gestação adolescente "a um erro cometido, que carece de ser pago, castigado e punido". As falas a seguir demonstram esses aspectos:

Quando eu recebi a notícia, eu fiquei bem preocupado e achei que meus pais iam me 
matar, coisa assim, até eu não, nem fui eu que contei pra eles, quem contou foi minha, minha ex-sogra, a mãe da N. (Gerson, 18 anos).

Bom, primeiro veio o nervosismo, né!? Como a gente era muito novo ainda, daí eu fiquei com medo de, tipo, não ter como sustentar a criança. Depois veio a hum... pensei na mãe, no pai dela, na minha mãe, nos meus... no meu padrasto, como que eles iam reagir, né!? (Giovanni, 18 anos).

Ah, eu fiquei feliz, né, quando a doutora lá falou que ela tava grávida. A gente fica feliz, né!? Não tem como não, não ficar alegre (Gilson, 18 anos).

Além da preocupação com a família, outro sentimento que se mostrou presente na vida desses pais adolescentes que não planejaram a gravidez foi o medo. Eles descreveram que tinham medo dessa situação nova (a paternidade), a qual interferiu na relação vivida com sua família e consigo mesmo. Um dos pais descreve o medo da responsabilidade que assumiria; outro indica que tinha medo de como seria o bebê, se este seria normal.

Báh, durante um bom tempo, eu continuei né, com, com medo, com preocupação, aí depois fui me acostumando com a ideia, fui até assim, me sentindo mais maduro, fui amadurecendo durante a gravidez (Gerson, 18 anos).

A literatura tem descrito que é natural ocorrerem sentimentos ambivalentes em relação aos filhos. De fato, tanto homens quanto mulheres podem ter sentimentos que vão desde a empolgação com a notícia até os sentimentos de ansiedade e medo em relação à responsabilidade de cuidar de um filho e ao comprometimento de tempo e de energia que isso envolve (Freitas, Coelho \& Silva, 2007; Staudt \& Wagner, 2008).

Em nosso estudo, as reaçóes iniciais de "choque" e medo foram sendo modificadas processualmente no decorrer da gestação; observa-se que os jovens, especialmente aqueles que continuam com a mãe da criança, passaram a se preocupar com o filho e a companheira, demonstrando sentimentos de cumplicidade e de comprometimento para com eles.

Como a gente era muito novo ainda, daí eu fiquei com medo de, tipo, não ter como sustentar a criança [...] Pensei em tudo, tudo, tudo, tudo, um misto de pensamento, como seria o nenê, se seria normal a gravidez. Se tudo ia ocorrer bem, pensei... em tudo [...] eu senti que, como a J. ficou mais sensível, né!? Ela ficou mais, mais sensível em tudo, ela precisava de... às vezes, ela precisava de ajuda, né!? Daí eu tentei acolher ela o máximo que eu pude (Giovanni, 18 anos).

Agora tá melhor, no início ela teve muito enjoo, né!? Eu sempre junto com ela, sempre ajudando ela e... ela vomitava, ficou dois meses vomitando direto (Gilson, 18 anos).

Dados similares foram encontrados no estudo de Levandowski e Piccinini (2006). Esses autores revelaram que os adolescentes pais apresentam as mesmas preocupaçóes e sentimentos dos adultos. Esses são comuns à situação de paternidade, como, por exemplo, a preocupação com o bebê e com a companheira. Já o pai que não mantinha mais o relacionamento com a mãe da criança não demonstrou preocupação com ela ou mesmo com o filho. Esse pai descreveu apenas preocupaçóes com seus projetos de vida. A fala a seguir demonstra o sentimento de medo vivenciado por esse pai face à responsabilidade que assumiria diante do nascimento da criança. Ele ressaltou que só pensava em ser pai depois que tivesse um trabalho.

Medo da responsabilidade que a gente vai assumir, da... como vai ser as coisas a partir do nascimento, mas no fim, é, deu tudo certo... eu pensava em ser pai bem mais pra frente assim... depois que eu tivesse me formado, depois que já tivesse um trabalho, a princípio por aí (Gerson, 18 anos).

De fato, percebemos que a experiência da paternidade no período da adolescência desperta sentimentos ambivalentes, tais como preocupação, medo, insegurança e alegria. Para os pais que receberam a notícia como algo inesperado, o medo foi o principal sentimento descrito; para o pai que planejou a gravi- 
dez, o sentimento de alegria permeou a experiência. O sentimento de preocupação com o futuro foi comum a todos, independentemente do planejamento ou não da gestação. O que mudou foi o tipo de preocupação dentro do contexto de vida de cada um deles.

Para os jovens de nossa pesquisa, ser pai está totalmente associado às concepçôes de gênero, nas quais o pai é o provedor. Então, para esses jovens, ser pai significa ser responsável e prover o sustento do filho. Trindade e Menandro (2002) também encontraram em seu estudo que ser pai significa, acima de tudo, trabalhar para prover as necessidades da criança, educando-a, oferecendo-lhe carinho e atenção. O sentimento de preocupação desses adolescentes diante da notícia da gravidez parece ser justificado, uma vez que esses jovens indicam que ainda não estáo totalmente preparados para assumir a condição de pai, mas já reconhecem que algumas responsabilidades os esperam.

A respeito disso, percebemos, em estudos sobre paternidade adulta e adolescente, que a preocupação, assim como outros sentimentos, são naturais tanto em homens como em mulheres, não se restringindo à adolescência (Freitas et al., 2007; Gabriel \& Dias, 2011; Krob, Piccinini \& Silva, 2009; Levandowski \& Piccinini, 2002; Staudt \& Wagner, 2008).

\section{Maior Responsabilidade e Redução da Liberdade}

De modo geral, o que mais se destacou na fala dos pais, independentemente de terem uma gravidez planejada ou não, foi o sentimento de responsabilidade que perceberam com o advento da gravidez. Todos eles se descrevem como mais responsáveis e maduros diante da notícia da gravidez; contudo, o significado do que é ser responsável assumiu diferentes configuraçôes para cada entrevistado.

De fato, Orlandi e Toneli (2008) observam que "as experiências vividas pelos jovens são plurais, bem como os sentidos atribuídos a tais experiências" (p. 319); desta forma, a paternidade parece assumir diferentes sentidos. Para um participante de nossa pesquisa, a gravidez mudou sua percepção sobre a vida escolar, ela o fez perceber que, para alcançar seus objetivos de vida futuro, seria necessário um maior comprometimento com os estudos. Para outro, a responsabilidade com o sustento do bebê o fez sentir-se pressionado. Já para um terceiro, seu relacionamento com a parceira melhorou, uma vez que partilhavam de algo que consideravam importante.
Hoje em dia, eu me sinto bem mais maduro do que eu era antes. Com mais responsabilidade, até porque durante a gravidez eu comecei a trabalhar, não só por causa da gravidez, sabe... por causa, assim, que eu já tava vendo um trabalho de meio turno pra conciliar com o colégio. Aí, foi durante a gravidez aí que deu certo (Gerson, 18 anos).

Sim... mudou muito, ih, tá louco! Me tornei mais responsável, hum... comecei a trabalhar (Giovanni, 18 anos).

\begin{abstract}
Ah, bem melhor que como era antes, nél? Tudo, tudo muda. Ah, a gente, a gente fica mais responsável, né!? Tem que cuidar do... d'um ser que não tem, não tem... como é que eu vou dizer?... Não tem defesa, né!? (Gilson, 18 anos).
\end{abstract}

Nogueira et al. (2011) destacaram que a vivência da paternidade gera dúvidas e angústias face à busca por um lugar no mundo dos adultos. $\mathrm{O}$ jovem ora se sente como adulto dotado de saber e responsabilidades, ora se sente como uma criança, que necessita ser cuidada. Em nosso estudo, além de maior responsabilidade, a paternidade gerou a inserçâo dos adolescentes no mercado de trabalho.

Esses pais descreveram ainda que a paternidade diminuiu seu tempo para conviver com os amigos e/ou gerou a perda da liberdade para se fazer o que se quer. Além disso, trouxe a necessidade de se preocupar em subsidiar financeiramente o filho e a companheira. Tal mudança faz parte das expectativas sociais em torno do papel de ser pai. Madeira (1997) e Sarti (2005) descreveram em seus estudos realizados com adolescentes de camadas populares que a divisão de papéis é bem demarcada, sendo atribuídas determinadas atividades para cada gênero. Os meninos desde cedo devem exercer atividades que objetivam prover a família. Quando a gestaçáo da namorada/ companheira ocorre, eles passam a trabalhar ainda mais para garantir o sustento de seu novo núcleo familiar, comprovando sua masculinidade por meio tanto da fecundação como da capacidade em garantir a sobrevivência da prole. Já às meninas cabe o cuidado do bebê e da casa. Os pais de nosso estudo compartilham dessas representaçóes. 
Agora eu me privo de algumas coisas assim, às vezes, eu não saio tanto, finais de semana, né, porque tem que ajudar, eu me controlo na gas..., na questáo financeira, também, né!? (Gerson, 18 anos)

Agora eu tenho que, tenho que trabalhar pra sustentar outra pessoa que depende de mim (Giovanni, 18 anos).

Meus plano é ter uma, uma parte financeira boa também, né!? E comprar um terreno pra fora, assim... fazer uma chácara. Ah, dar tudo de melhor pros dois, né!? (Gilson, 18 anos).

Todos os pais de nosso estudo descreveram que suas vidas mudaram após a notícia da gravidez. Ressaltaram que tiveram de abrir mão de algumas prioridades pessoais para estar próximo do filho e/ou da mãe da criança. O lazer dos participantes é reordenado dentro de uma nova rotina que inclui o trabalho e uma maior inserção na vida doméstica, em detrimento da vida social individual. Dois pais descreveram que tiveram de abandonar as atividades lúdicas, mais associadas à vida infanto-juvenil, como jogar video game e participar de campeonato de bicicleta.

Sim, amigos, final de semana, eu ia pra boate, alguma coisa, jogava video game às vezes, em casa, sei lá... e agora faço menos (Gerson, 18 anos).

Eu tinha mui... bastante amigos, assim... eu saía, jogava bola, ia em festa, um monte de coisa. Bom, eu gosto de sair, né. Eu saía mais, eu ia na casa... eu ia nos meus parentes. Aí que agora ficou meio que restrito, né. É o trabalho e a casa, o trabalho e a casa (Giovanni, 18 anos).

Ah, eu saía bastante, eu fazia campeonato de bicicleta, né, lá fora, assim... no mato, no barro. Saía com a turma... e depois que eu comecei a namorar sério mesmo... mudou bastante, né!? [...] Os amigos é mais pra diversão e daí ã, a minha esposa, por exemplo, é coisa séria, né!? Nada de brincar, tem que ter cuidado na hora de tudo. Antes era muito... gostava de sair com a gurizada, né!? Agora, é, parou, né!? Agora ficou... só eu e ela. É uma vida nova, né!? (Gilson, 18 anos).

Apesar de esses jovens pais vivenciarem uma gravidez em um período náo esperado, todos consideraram ter obtido ganhos em face da experiência da paternidade e, mais especificamente, com o nascimento do bebê. O aumento da responsabilidade também foi percebido de maneira positiva. Um dos participantes identificou que a gravidez o fez dar um novo sentido ao seu projeto de escolarização. Outro revelou ter assumido a responsabilidade de trabalhar para sustentar a criança. Já o pai que planejou a gravidez descreveu que a mudança mais significativa que vivenciou foi a transformação de sua relação com a parceira. Para ele, o fato de a criança fazer parte de si e da companheira (mãe) fez com que o casal se cuidasse na sua maneira de dialogar.

Olha, eu estudava, aí, era mais diversão, né, eu, não, é, eu não tinha amadurecido tanto como agora, eu saía mais, eu não parava em casa e gastava mais dinheiro com bobagem também, daí que hoje em dia eu procuro evitar (Gerson, 18 anos).

Eu era estudante, não tinha muita pressão, né!? Só mais era estudo. Agora, não. Agora tenho que trabalhar para sustentar outra pessoa que depende de mim (Giovanni, 18 anos).

Antes, a gente se falava um pouco mais grosso um com o outro. Agora, tá tudo levezinho, né!? Com o nenê junto! (Gilson, 18 anos).

A literatura tem descrito que a paternidade nesse período de vida pode ser percebida e sentida como um evento que traz maiores responsabilidades e também dificuldades. No entanto, também pode ser considerado como um evento positivo. Por exemplo, no estudo realizado por Melo, Machado, Maia e Sampaio (2012), os jovens pais relataram que a res- 
ponsabilidade é um aspecto positivo da paternidade, pois faz com que busquem a inserção profissional. Além disso, o bebê também traz satisfação aos pais. Essa satisfaçáo experimentada pelos pais pode ser derivada, por exemplo, do sentimento de serem bons pais e estarem afetivamente próximos de seus filhos, vivenciando de forma efetiva o seu desenvolvimento (Silva \& Piccinini, 2007).

\section{Mudanças nos Diferentes Contextos de Vida dos Participantes a Partir de suas Percepçóes}

Nesta segunda categoria, os participantes foram solicitados a descrever as mudanças que ocorreram no contexto familiar, no grupo de pares, no contexto escolar e de trabalho, ocorridas a partir da gravidez. Essa categoria foi subdividida em outras duas: Apoio familiar e Mudanças na vida escolar e trabalho.

\section{Apoio Familiar}

Apesar de terem vivenciado os sentimentos de medo e de preocupação diante da notícia da gravidez para os pais, os participantes que não haviam planejado a situação encontraram apoio e compreensão da família, principalmente de suas mães. No entanto, o pai que planejou a gravidez junto à namorada encontrou maiores dificuldades de encontrar esse apoio. De acordo com esse adolescente, seus pais eram "chatos" e não permitiam que ele saísse. No entanto, depois que se envolveu com a mãe de seu bebê, as coisas mudaram, seus pais passaram a liberá-lo. Talvez esse fato se associe à questão que pode explicar o motivo que o levou a planejar a gravidez com a companheira.

Durante a gravidez, eu ficava bem mais emotivo assim, até com a minha família, eu achava que eles iriam receber assim, bem de forma... mais agressiva comigo, assim, me xingando, me... sabe? Mas não, eles foram calmos, até porque eles passaram por isso também, né!? Eles tiveram eu meio cedo também, não tão cedo como eu. Aí, eles, me, me acolheram bem, foram pacientes, conversaram comigo, me deram apoio (Gerson, 18 anos).

Bom... a minha mãe, a minha mãe ela, ela, adorou. Pra ela, foi um sonho, né, que ela, ela já tinha outros netos, mas ela adora a criança. E ela foi a que mais me apoiou... quando ela soube (Giovanni, 18 anos).

No início, eles não aceitaram muito assim, mas depois eles ficaram, â, ficam babando agora, né, no nenê. Aí, quando a C. vai lá em casa, eles ficam olhando, passando a mão na barriga e perguntando (Gilson, 18 anos).

Meincke e Carraro (2009), ao investigarem a vivência da paternidade adolescente e os sentimentos expressos pela família do jovem, encontraram que, apesar de a família vivenciar sentimentos de "choque" inicial, surpresa e preocupação, os familiares acabam por apoiar seus filhos. As autoras destacaram que, mesmo com as alteraçóes que a gravidez gera na vida dos jovens pais, eles se adaptam à nova situação, uma vez que o apoio familiar e das redes sociais envolvidas lhes oferecem apoio e facilitam esse processo de adaptação ao novo papel de pai.

Dias e Aquino (2006), também em uma pesquisa com jovens pais e mães de três cidades brasileiras, identificaram que a família constitui-se em uma importante fonte de apoio material, independentemente do segmento social e da situação de corresidência com o jovem. Nosso estudo indicou que a família se envolve na ajuda e no sustento dos jovens e de suas crianças.

Além do apoio, outra diferença percebida pelos participantes deste estudo foi que a família pareceu dar maior credibilidade e incentivo aos seus projetos de vida. Percebe-se, a partir da fala dos adolescentes, que a justificativa para essa aposta da família refere-se ao fato de esses jovens estarem adquirindo maior responsabilidade a partir da ocorrência da gravidez. Contudo, isso nem sempre ocorre, como pudemos observar no caso de Giovanni.

Antes, era só eu, agora, eles acham que, além deu pensar em mim, pensar na minha filha também, né!? Daí, agora, eles deram que meio uma travada, né!? Achando que eu preciso me dedicar mais ainda do que eu me dedicava antes (Giovanni, 18 anos).

Acho que, hoje em dia, até apostam mais em mim, porque eles viram, eles veem 
que eu, que hoje em dia eu quero mais, â, tenho bem mais planos pro futuro que eu tinha antes, daí eles apostam mesmo mais em mim. Eles veem que eu melhorei, que eu cresci mesmo (Gerson, 18 anos).

\section{Mudanças na Vida Escolar e Trabalho}

Orlandi e Toneli (2008) identificaram que a interrupção dos estudos dos pais participantes de sua pesquisa acontece em momentos anteriores à ocorrência da gestaçâo da parceira. Assim, para os autores, não é a gravidez que determina a evasão escolar, mas sim outras dificuldades que o jovem possui. Por outro lado, Cabral (2002) considera, por meio de estudos realizados sobre a trajetória escolar e profissional do jovem, que a gravidez nesse período acarreta prejuízos, principalmente no que se refere ao processo de escolarização e à aquisição precoce da responsabilidade financeira, pelo ingresso antecipado no mercado de trabalho. Em nossa pesquisa, apenas um pai entrevistado continuou os estudos; os outros dois participantes tiveram a notícia da gravidez durante os estudos secundários, mas conseguiram concluir o mesmo com a ocorrência da gravidez. Observa-se que a gravidez não foi um fator que impediu um dos pais de continuar os estudos; ao contrário, de acordo com Gerson, a gravidez o fez pensar ainda mais na importância do estudo em sua vida. Ele ressalta que:

Uma coisa que mudou bastante, antes eu, como aumentou a minha responsabilidade depois da gravidez, sendo que antes eu, eu ia mais pra brincar e não sabia o que fazer, depois, não dava tanta importância, depois da gravidez aumentou bastante, porque era daí eu tava, não era mais só o meu futuro, né, tinha o futuro de mais pessoas envolvidas, como até hoje é, aí acaba que a gente acaba levando mais a sério, aprendi (Gerson, 18 anos).

Mesmo tendo conseguido terminar o Ensino Médio, um dos pais alegou sentir-se pressionado com a ocorrência da gravidez, uma vez que precisou trabalhar para sustentar outra pessoa que depende dele a filha. Ele diz que:

Eu era estudante, não... não tinha muita pressão, né!? Só mais era estudo. Agora não, agora eu tenho que trabalhar para sustentar outra pessoa que depende de mim (Giovanni, 18 anos).

Já o outro pai alegou nunca ter levado muito a sério os seus estudos. Segundo ele, durante o período escolar, as atividades que mais o interessavam eram as esportivas. Gostava da disciplina de Educação Física por praticar esportes como basquetebol e, nas demais matérias escolares, considerava-se um aluno mediano.

\begin{abstract}
Ah, na escola, na parte de... das disciplina, assim... era médio, né!? Não era bom e nem ruim. Eu praticava bastante esporte... basquete, tinha time... Educação Física eu sempre fui bom, né!? É, no resto sempre fui médio. Nunca levei muito a sério assim, gostava mais da parte esportiva (Gilson, 18 anos).
\end{abstract}

Nota-se que, apesar da ocorrência da gravidez, os projetos de escolarização foram vividos por esses pais de acordo com as particularidades de cada experiência de vida. Um dos pais alegou ter se sentido mais responsável nos estudos por associar o seu futuro ao futuro da filha, pois entende que não é apenas o seu futuro que está em jogo agora, mas também o da filha. Já outro pai que se sentiu pressionado, mesmo tendo terminado os estudos, náo pretende dar continuidade aos mesmos, mencionando apenas que pretende trabalhar para dar sustento à filha. Por fim, o terceiro pai revela náo ter levado os estudos a sério, demonstrando que náo foi a ocorrência da gravidez que o impediu de dar continuidade aos mesmos, mas sim o fato de não se interessar pelas disciplinas.

No que se refere ao trabalho, Dias e Aquino (2006) verificaram que os jovens pais, comparados aos não pais, se inserem mais cedo no mercado de trabalho por se sentirem responsáveis em prover o sustento dos filhos e reafirmar socialmente sua identidade masculina perante a sociedade. Comparando esse dado com o da nossa pesquisa, salienta-se que os jovens entrevistados também demarcaram seu lugar de maior responsabilidade na medida em que se preocupavam com o sustento da criança e, em virtude disso, afirmavam a importância do trabalho em suas vidas.

Nogueira et al. (2011) consideram que a paternidade adolescente foi vivenciada como um divisor 
entre a vida infantil e a vida adulta, configurando-se como um passaporte para a vida adulta. A paternidade convoca os adolescentes a ocuparem novos lugares e assumirem novos papéis, ressignificando seus projetos de vida. De fato, no estudo de Melo et al. (2012), os adolescentes pais tiveram de se inserir no mercado de trabalho, assumindo responsabilidades que antes náo tinham, como prover o sustento de uma família.

A respeito do trabalho, apenas um dos participantes de nossa pesquisa não se encontrava no mercado de trabalho. Esse pai decidiu, por incentivo da mãe, deixar o trabalho para fazer cursinho preparatório para o vestibular de administraçáo. Esse pai conta que:

A gente falava sobre o que que eu queria fazer, né, me formar. $\mathrm{O}$ que queria fazer na faculdade, concurso, aí eu não tinha certeza. Daí, a mãe mais eu sempre falava, né!? A gente conversava bastante sobre a faculdade, eu também, que nesse tempo, que eu também, quero entrar no NPOR, né, coisa de quartel, pra mim ficar meio turno no quartel e meio turno eu faço faculdade (Gerson, 18 anos).

Cabe ressaltar que não é apenas o incentivo dos pais que pode ter influenciado o pai que se mostrou mais comprometido com seu projeto de vida de pleitear uma carreira de administrador. Outro fator, não menos importante, é o sentido de comprometimento que este passou a dar em seu projeto de escolarização depois da ocorrência da gravidez. Diferentemente desse pai, os outros dois participantes nâo se encontravam pleiteando o mesmo futuro, por meio de um curso superior, mas buscavam, a partir do trabalho atual de pintor e motoboy, o sustento próprio e de seus bebês. Priorizaram o trabalho e não o estudo em seus projetos de vida. Essas diferenças podem ser provenientes do contexto familiar e social dos jovens, já que a literatura tem descrito que os projetos de vida são diferentes de acordo com cada contexto social (Brandão \& Heilborn, 2006).

\section{As Concepçóes que os Pais Adolescentes possuem sobre o Papel Paterno}

Nesta categoria, os participantes buscaram descrever as características que eles imaginam que um bom pai possui. Ainda, questionamos os participantes sobre como eles descreveriam o seu relacionamento com o bebê ao se imaginarem como pai. Essa categoria foi desmembrada em duas subcategorias: O que torna um pai um bom pai e As dificuldades em se imaginar como pai.

\section{O que Torna um Pai um Bom Pai}

Para os participantes, um bom pai ou o pai ideal é descrito como aquele que está sempre junto com o filho; é presente na vida da criança, participando, comunicando-se e demonstrando cuidado e paciência com o filho. Alguns participantes relataram que seus próprios pais eram suas referências de "bom pai"; outros colocaram que o pai que tiveram não foi um parâmetro norteador para ser um bom pai atualmente. Os participantes ressaltaram ainda que aquilo que lhes faria perceber se estavam atuando como bons pais era a convivência e o relacionamento com o filho.

Hoje em dia, é muito bom, eu vejo ela, não vejo todos os dias, mas vejo quase todos, assim, umas cinco, seis vezes por semana, eu vejo ela, ã, espero que continue sempre assim, não sei, se no caso eu e a mãe dela no futuro, a gente vai voltar a ficar junto, mas se ela náo morar comigo eu quero ter um relacionamento com ela bem próximo, ser amigo dela, â, ter um diálogo muito bom com ela, sempre poder orientar, as coisas certas e erradas, pra tornar ela a melhor pessoa possível, né!? Eu acho que eu gostaria de ser a mistura do meu pai e da minha máe juntos (Gerson, 18 anos).

A gente olhando o filme a gente adora, né!? Aquela cena que os pais saem com os filhos, beija os filhos, daí a gente quer aquilo, né!? Bom... eu não tive um bom pai, né?? Isso eu posso te dizer, mas assim... tem bastante pessoa que eu acredito que seja um bom pai. Agora, agora eu náo tenho nenhuma referência (Giovanni, 18 anos).

Um bom pai é aquele que tá sempre junto com o filho, né!? Não deixa o filho de lado pra fazer outras coisas. Tem que deixar o filho sempre junto, né!? Sempre junto no relacionamento também (Gilson,18 anos). 
Conforme verificado na fala desses jovens, a paternidade traz consigo o caráter de cuidado e companheirismo; para eles, ser pai é, acima de tudo, ter a presença na vida dos filhos. Bornholdt, Wagner e Staudt (2007) destacam que a percepção de jovens pais sobre a gravidez como um período de transição ao exercício da paternidade está diretamente associada à inclusão e à participação destes na vida dos filhos.

Foi possível identificar, neste estudo, a importância que esses jovens conceberam no relacionamento com os seus filhos, pois apontaram que é a partir da convivência com a criança que saberiam se são ou não bons pais. No estudo realizado por Gabriel e Dias (2011), os pais adultos mencionaram que o relacionamento com os próprios pais lhes servia como referência, podendo o modelo de paternidade ser repetido ou rechaçado.

\section{Dificuldades em se Imaginar como Pais}

Quando perguntado aos adolescentes quais seriam seus projetos de vida futuros, principalmente no que se referia a eles próprios enquanto pais, apenas um entrevistado conseguiu responder à questão; os demais participantes apresentaram dificuldades de se imaginar em tal situação, mesmo aqueles que já tinham o bebê. Ao ouvirem a pergunta "como você se imagina como pai?", responderam:

Fácil, fácil não vai ser, né!? Eu... assim, não, não tô conseguindo pensar muito... eu não tô conseguindo responder essa pergunta (Gerson, 18 anos).

Bom, eu tento fazer o melhor possível que eu posso, né!? Espero que, no futuro, ela seja uma boa pessoa. Ficá na conversa assim, né, que a gente conversa, daí a gente consegue manter uma relação, assim, de pai e filha que, com o tempo, ela vai aumentando, né!? (Giovanni, 18 anos).

Como que eu me imagino? Báh, essa pergunta aí eu não sei responder não (Gilson, 18 anos).

Ao se analisar as falas dos participantes quanto às dificuldades de se imaginar como pai, encontram-se resultados semelhantes aos descritos por Trindade e Menandro (2002). Esses autores observaram que os pais adolescentes assumem a responsabilidade de pais, mas náo se reconhecem como tal. Isso porque o processo identificatório com a paternidade é mais lento de ser construído, sendo que, para alguns pais adolescentes, ele pode não chegar a se desenvolver devido às próprias dificuldades da adolescência, pois é nesse período que o indivíduo constrói sua identidade. Quando o adolescente se torna pai nesse período de vida, possui dupla tarefa - ser filho e ser pai.

Levandowski e Piccinini (2006), em uma pesquisa realizada com adolescentes que estavam passando pela situação da gravidez do primeiro filho, verificaram que, mesmo descrevendo-se no futuro relacionamento com a criança, os adolescentes passaram uma impressão de ainda estarem distantes de seu papel de pai. Os autores justificaram que talvez essa dificuldade ocorresse em função da falta de modelos paternos. Dessa forma, os futuros pais sentiam-se perdidos e confusos quanto ao que esperar desse novo papel. Além disso, existiriam novas demandas referentes à função de pai. De acordo com Wagner, Predebon, Mosmann e Verza (2005), atualmente se exige mais dos homens para que eles participem da educação e cuidado do filho, o que pode dificultar ainda mais esse processo de construção da paternidade para os jovens pais.

Por outro lado, Carvalho, Merighi e Jesus (2009) destacaram que a dificuldade que os pais adolescentes possuem em projetar-se no futuro estão diretamente associadas às condiçóes objetivas de vida dos jovens, vinculadas à alimentação, moradia, vestuário, sustento da família, entre outros. Isso ilustra o que Levandowski e Piccinini (2002) descrevem sobre a parentalidade na adolescência que insere os adolescentes no mundo adulto das responsabilidades, porém não tira as especificidades da adolescência. A paternidade implicaria em problemas adicionais para o indivíduo na medida em que não haveria uma organização social para preparar e apoiar os jovens nessa nova tarefa e fase de vida.

\section{Consideraçóes Finais}

Os objetivos deste estudo foram compreender alguns aspectos envolvidos no fenômeno da paternidade adolescente, identificando-se as principais mudanças ocorridas na vida desses jovens a partir de suas próprias percepções sobre o fenômeno. Com a 
realização das três entrevistas e análise das mesmas, foram identificadas três grandes categorias descritoras do fenômeno, a saber: Mudanças pessoais, Mudanças nos diferentes contextos de vida dos participantes a partir de suas percepçóes e As concepções que os pais adolescentes possuem sobre o papel paterno.

Cabe ressaltar que, embora existam diferenças na condição dos pais entrevistados face ao nascimento do bebê, não foram observadas diferenças significativas nos depoimentos dos mesmos no que se refere aos objetivos do estudo. Destaca-se que alguns autores revelam que existem mudanças nos papéis e no exercício da paternidade nesses dois períodos; assim, considera-se que maiores estudos devem ser desenvolvidos enfocando essas diferenças, uma vez que não foram o foco deste trabalho (Bornholdt, 2002; Castoldi, 2002 Martini, 1999 Parke, 1986).

De maneira geral, observamos que, apesar de a paternidade na adolescência ser um acontecimento não esperado para esse período de desenvolvimento, os participantes deste estudo perceberam diferentes ganhos em suas vidas decorrentes do advento da gravidez e, consequentemente, da paternidade. A responsabilidade foi apontada pelos jovens como um fator positivo em suas vidas, na medida em que os fez procurar outras formas de viver face à situação. A paternidade pôde trazer o comprometimento de um dos pais com seu projeto de escolarização. Para os outros dois pais, os planos futuros mostraram-se relacionados a projetos laborais.

Nesse aspecto, percebemos que nem sempre a paternidade assume um caráter negativo na vida dos jovens, como é representado, frequentemente, pela literatura. Ressaltamos, ainda, que o apoio familiar é um fator importante para a construção e desenvolvimento do projeto de vida futuro desses jovens, já que o auxílio financeiro e emocional dos pais oferece uma base para a construção da identidade e autonomia dos jovens. No entanto, é claro que os jovens enfrentam dificuldades em sua transição para a paternidade, principalmente no que se refere à perda da liberdade e à dificuldade de se imaginarem como pai. Porém, os participantes descrevem que procuram se adaptar à nova situação.

Talvez a contribuição mais importante deste estudo tenha sido mostrar que nem sempre a paternidade é vista como negativa no período da adolescência. Nesse sentido, observamos a necessidade de um maior número de estudos que contemplem o pai adolescente diante das suas expectativas, sentimentos e percepçôes com a ocorrência da paternidade. Ainda cabe destacar a importância de políticas públicas voltadas a esse público, pois é visível que apenas a mãe adolescente recebe a devida atenção, sendo, portanto, esquecidos os jovens pais na mesma situaçáo.

Por fim, destacamos que não pretendemos, com este estudo, fazer generalizaçôes, mas sim compreender alguns aspectos envolvidos no fenômeno da paternidade na adolescência a partir do estudo de três casos. A amostra não é representativa da população de pais adolescentes; assim, não se esgotaram as possibilidades de experiência desses pais relacionadas à paternidade. Foram acessados apenas depoimentos de pais adolescentes dispostos a participar do estudo. Sugere-se, para próximos estudos, tanto uma ampliação da amostra de pais (visando aumentar a variabilidade de experiências descritas possíveis) como a realização da coleta de depoimentos com os pais em diferentes momentos (o que possibilitaria a identificação de mudanças nas percepçóes dos pais sobre as alteraçóes em suas vidas e concepções sobre paternidade).

\section{Referências}

Bardin, L. (1977). Análise de Conteúdo. Lisboa: Edições 70.

Bornholdt, E. A. (2002). Gravidez e paternidade: a vivência do pai grávido. Dissertação de Mestrado não publicada. Faculdade de Psicologia da Pontifícia Universidade Católica do Rio Grande do Sul, Porto Alegre.

Bornholdt, E. A., Wagner, A., \& Staudt, A. C. P. (2007). A vivência da gravidez do primeiro filho à luz da perspectiva paterna. Psicologia Clínica, 19(1), 75-92.

Brandão, E., \& Heilborn, M. (2006). Sexualidade e gravidez na adolescência entre jovens de camadas médias do Rio de Janeiro, Brasil. Cadernos de Saúde Pública, 22(7), 1421-1430.

Cabral, C. S. (2002). Gravidez na adolescência e identidade masculina: repercussóes sobre a trajetória escolar e profissional do jovem. Revista Brasileira de Estudos de População, 19(2), 180-195.

Carvalho, G. M., Merighi, M. A. B., \& Jesus, M. C. P. (2009). Recorrência da parentalidade na adolescência na perspectiva dos sujeitos envolvidos. Texto \& Contexto Enfermagem, 18(1), 17-24.

Castoldi, L. (2002). A construção da paternidade desde a gestação até o primeiro ano do bebê. Tese de Doutorado não publicada. Universidade Federal do Rio Grande do Sul, Porto Alegre. 
Dias, A. B., \& Aquino, E. M. L. (2006). Maternidadee paternidade na adolescência: algumas constataçóes em três cidades do Brasil. Caderno de Saúde Pública, 22(7), 1447-1458.

Freitas, W. M. F., Coelho, E. A. C., \& Silva, A. T. M. C. (2007). Sentir-se pai: a vivência masculina sob o olhar de gênero. Cadernos de Saúde Pública, 23(1), 137-145.

Gabriel, M. R., \& Dias, A. C. G. (2011). Percepçōes sobre a paternidade: descrevendo a si mesmo e o próprio pai como pai. Estudos de Psicologia, 16(3), 253-261.

Grossman, E. (2010). A construção do conceito de adolescência no Ocidente. Revista Saúde \& Adolescência, 7(3), 47-51.

Jorgensen, S. R. (1993). Adolescent pregnancy and parenting. In T. P. Gullota, G. R. Adams, \& R. Montmayor (Eds.), Adolescent sexuality (pp. 5776). Newbury Park: Sage.

Krob, A. D., Piccinini, C. A., \& Silva, M. R. (2009). A transição para a paternidade: da gestaçáo do segundo mês de vida do bebê. Psicologia USP, 20(2), 269-291.

Lewandowski, D. C. (2001). Paternidade na adolescência: uma breve revisão da literatura internacional. Estudos de Psicologia, 6(2), 195-209.

Lewandowski, D. C., Koller, S., \& Piccinini, C. A. (2002). Paternidade na adolescência e os fatores de risco e de proteção para a violência na interação pai-criança. Interaçôes, 7(13), 77-100.

Lewandowski, D. C., \& Piccinini, C. A. (2002). A interação pai-bebê entre pais adolescentes e adultos. Psicologia: Reflexão e Crítica, 15(2), 413-424.

Lewandowski, D. C., \& Piccinini, C. A. (2006). Expectativas e sentimentos em relação à paternidade entre adolescentes e adultos. Psicologia: Teoria $e$ Pesquisa, 22(1), 17-28.

Madeira, F. R. (1997). Quem mandou nascer mulher? Estudos sobre crianças e adolescentes pobres no Brasil. Rio de Janeiro: Record; Rosa dos tempos.

Martini, T. A. (1999). A transição para a paternidade: expectativas, sentimentos e sindrome de Couvade nos futuros pais ao longo da gestação. Dissertação de Mestrado não publicada. Universidade Federal do Rio Grande do Sul. Porto Alegre.

Meincke, S. M. K., \& Carraro, T. E. (2009). Vivência da paternidade na adolescência: sentimentos expressos pela família do pai adolescente. Texto \& Contexto Enfermagem, 18(1), 83-91.

Melo, A. L., Machado, M. F., Maia, E. R., \& Sampaio, K. J. (2012). Repercussóes da paternidade na vida do adolescente. Revista da Rede de Enfermagem do Nordeste, 13(2), 261-268.
Minayo, M. C. S. (1993). O Desafio do conhecimento: pesquisa qualitativa em saúde (2a Ed.). São Paulo: Hucitec; Abrasco.

Moreira, T., Viana, D., Queiroz, M. V., \& Jorge, M. S. (2008). Conflitos vivenciados pelas adolescentes com a descoberta da gravidez. Revista da Escola de Enfermagem da USP, 42(2), 312-320.

Nogueira, M., Martins, A., Schall, V., \& Modena, C. (2011). "Depois que você vira um pai...": adolescentes diante da paternidade. Adolescência \& Saúde, 8(1), 28-34.

Orlandi, R., \& Toneli, M. J. F. (2008). Adolescência e paternidade: sobre os direitos de criar projetos e procriar. Psicologia em Estudo, 13(2), 317-326.

Parke, R. D. (1986). El papel del padre. Madrid: Ediciones Morata.

Reis, A. O. (1997). Opacidade e visibilidade da paternidade na reproduçáo adolescente. Revista Brasileira de Crescimento e Desenvolvimento Humano, 7(2), 69-76.

Sarti, C. (2005). A família como espelho: um estudo sobre a moral dos pobres (3a Ed.). São Paulo: Cortez.

Silva, M. R., \& Piccinini, C. A. (2007). Sentimentos sobre a paternidade e o envolvimento paterno: um estudo qualitativo. Estudos de Psicologia (Campinas), 24(4), 561-573.

Staudt, A. C. P., \& Wagner, A. (2008). Paternidade em tempos de mudança. Psicologia: Teoria e Prática, 10(1), 174-185.

Trindade, Z. A., \& Menandro, M. C. S. (2002). Pais adolescentes: vivência e significação. Estudos de Psicologia (Natal), 7(1), 15-23.

Wagner, A., Predebon, J., Mosmann, C., \& Verza, F. (2005). Compartilhar tarefas? Papéis e funções de pai e mãe na família contemporânea. Psicologia: teoria e pesquisa, 21(2), 181-186.

\section{Endereço para correspondência:}

Ana Cristina Garcia Dias

Rua Marechal Floriano Peixoto, 1.750, sala 308 Centro

CEP 97015-372 - Santa Maria/RS

E-mail: anacristinagarciadias@gmail.com

Recebido em 01/08/2012

Revisto em 24/12/2012

Aceito em 31/01/2013 